\title{
The Development of Inter-Disciplinary Belief Systems: The Effect of Academic Disciplines
}

\author{
Michael S. Puddicombe ${ }^{1 *}$
}

\begin{abstract}
In considering the skill set AECO professionals bring to bear in the realization of the built environment those that address technical issues are usually considered preeminent. However, when issues move beyond those that can be solved by an individual, interpersonal skill may become equally important. Technical and interpersonal skills have a major impact on the nature of the inter-disciplinary relations that define the AECO industry and these relations are major contributors to the outcome of a project. The foundation for the technical skills is acquired through a set of prescribed courses during a student's college education. These skills result from a pedagogical approach that results in explicit knowledge. We argue that the interpersonal skills and beliefs are also developed during this period. However, they are predominately a by-product of the pedagogical approach and result in tacit knowledge that prescribes a mode of interaction with other professionals. In this paper we begin to map this interpersonal skill set. We explore facets of this skill set and how a student's tacit interpersonal skills change over the course of their college career. Understanding what students perceive as 'truths' and how these truths change during their educational experience will help us to develop pedagogical approaches that result in more effective inter-disciplinary relationships and ultimately superior projects.
\end{abstract}

\section{Keywords}

Inter-disciplinary Behavior, Machiavellianism, Factor analysis, ANOVA

\footnotetext{
${ }^{1}$ Norwich University, David Crawford School of Engineering, Department of Civil \& Environmental Engineering and Construction Management, 150 Midway Road, Northfield, VT 05663, *Corresponding Author: E-mail: mpuddico@norwich.edu
} 
perceived to impact the functioning of the AECO team. We employ the concept of Machiavellianism (Mach) as developed by Christie and Geiss (1970) to begun to understand the tacit learning that results in this often contentious dynamic. Their work has laid the foundation for a significant body of research that has examined a wide range of issues related to how individuals function in group situations. While Machiavellianism has been shown to be a multi-dimensional construct it is often associated with the belief "that the ends justify the means". This perception combined with a social desirability bias has resulted in a negative perception of the term Machiavellian. This study maintains a neutral view towards the construct and employs it as a lens that allows a clearer understanding of the impact of our educational processes.

In the first part of the paper we conduct a literature review that has three parts. The first part briefly reviews the literature of collaboration in general and within the AECO industry. We then examine the emerging literature on interdisciplinary learning in the AECO disciplines. As part of this effort we also briefly examine the positions of the various accrediting bodies as it relates to position and behavior within an AECO context. Lastly, we introduce previous research on Machiavellianism that provides the basis for our study. Based on this foundation we develop a number of hypotheses as well as describe the student's beliefs relative to inter-disciplinary behavior. In order to capture the change that we hypothesize to occur we conducted a study employing the Mach IV survey. It was administered to a cohort of freshman and senior students in Architecture, Engineering, Construction and Management in 2013. The results of this survey were analyzed using factor analysis and ANOVA. We conclude with a discussion of the results and suggestions for future research.

\section{Literature Review}

\section{The Industry}

Collaboration between professionals with different disciplinary backgrounds is a complex and 
dynamic process defined by individuals from different 'thought worlds.' The result is often a lack of synthesis among experts and a reduction in the learning that is necessary for innovation (Dougherty, 1992). While the diversity resulting from these thought worlds is critical in the development of new knowledge it also presents challenges that if not managed effectively can at a minimum result in sub optimization but often result in failure to achieve project goals. Within the AECO industry this condition appears to be far from the exception (Puddicombe, 1997).

The complex nature of this variation has resulted in significant inefficiencies in the interrelationships between people and firms. Lavikka etal (2016) reported on efforts to integrate the owner organization and the AEC team in a large complex building project. They describe a process of dialogue, trust building, and shared understanding that are required for successful collaboration. While few would disagree with this model the efforts to implement it can be formidable. Efforts to build trust can be especially daunting. In this case it took approximately one year to build trust.

The requirement for multi-disciplinary collaboration rests on the assumption that, "...no single individual (or firm) can acquire the varied and often rapidly expanding information needed for success. Individuals (and firms) must work together to collect, analyze, synthesize and disseminate information throughout the work process." (Sonnenwald, 2000:461) This assumption is particularly poignant in the construction industry due to its unique form and operation. It is a basic industry, but unlike many manufacturing industries it more accurately reflects a "conglomerate of industries" (FernandezSolis 2009). It is defined by variation in the environment, the inputs, and the participants.

The structure of the industry and the complexity of the projects result in interactions that are characterized by misunderstanding and conflict (Emmit 2007). When problems emerge professional's will tend to focus on those issues and solutions that are associated with their profession (Gameson, 1992). They will also try to direct the outcome such that it provides the maximum benefit to themselves and their organizations (Loosemore,
1996). This situation describes a condition of contested collaboration "... where team members maintain an outward stance of cooperation but work to further their own interests, at times sabotaging the collaborative effort." (Sonnenwald $2000,461)$ This condition would be supported by the diffuse responsibility and authority that is embedded in a project (Love, 2004).

Emotional intelligence is one area related to collaboration skills that has elicited a significant amount of study in relationship to the AEC industry. These studies have shown significant challenges. Songer \& Walker (2004) show that General Contractor employees score lower on EI than the population as a whole and that tenure in the industry is associated with lower levels of EI. Lindeman and Cassell (2012) suggest that the context of the industry may make efforts at increasing EI extremely difficult if not doomed to failure. There is also the suggestion (Lindeman and Jordan, 2012) that EI is to altruistic to be effective in a competitive AEC environment. Despite this EI is seen as a necessity skill set for future industry leaders (Songer etal, 2006).

Contested collaboration reflects a Machiavellian approach to the project where each party strives to create and sustain a power base (Liu 2006). As the actors struggle to protect their position, conflicts will increase. The distribution of power allows each party to take ownership of their portion of the project and in theory prevent one party taking more power than the other. This state can hinder project progress by compartmentalizing communications in an attempt to impose their power level. This reduction in the flow of information will negatively impact multiple facets of the project (Patterson 2008). Despite this contentious environment research (Puddicombe, 2007) suggests that AEC actors have not adopted Machiavellian beliefs. Industry professionals across disciplines scored on the low range (61-62) as measured by the Mach IV scale.

Professional organizations have begun to respond to this state and its negative affect on the requirement for collaboration. The American Institute of Architects (AIA) has released the A295 family of contracts focused on facilitating 'Integrated Project Delivery.' ConsensusDocs, a 
consortium of 33 industry associations (including the Associated General Contractors of America (AGC) and Construction Users Roundtable (CURT)), has issued the 300 series of contracts titled the Collaborative Documents (ConsensusDocs 2016).

While contracts are an important and highly visible artifact they are just that an artifact. It is the enactment of the contract by individuals that will determine the success of collaboration and the effect on the project. Latham (1994) and Egan (1998) produced major reports for the British government that emphasized the necessity of collaboration. They emphasize the need for teamwork and the requirement to rethink the importance of interpersonal skills.

\section{The Academy}

Puddicombe (1997) offered evidence that performance within the built environment required a movement away from planning as an isolated linear process. An iterative process based on learning was required (Figure 1).

The reality of an academic environment places constraints on the amount of learning that can result from the actual execution of the plan. However, an interdisciplinary academic environment can readily support learning that results from the planning process. In that context we argue that understanding the dynamics of a collaborative learning environment is critical.

Emotional Intelligence has been suggested to be an important factor in collaboration and recent studies have examined the relationship between (EI) and pedagogical context. In a study of civil engineering and liberal arts students the civil engineering students were found to have no growth in there EI over their four-year period where the liberal arts students did experience growth (Chinowsky and Brown, 2004). Another study (Mo etal, 2007) found no differences between students of the various AEC disciplines in terms of their EI levels. In addition, they found that the students scored at the lower end of reported scores.

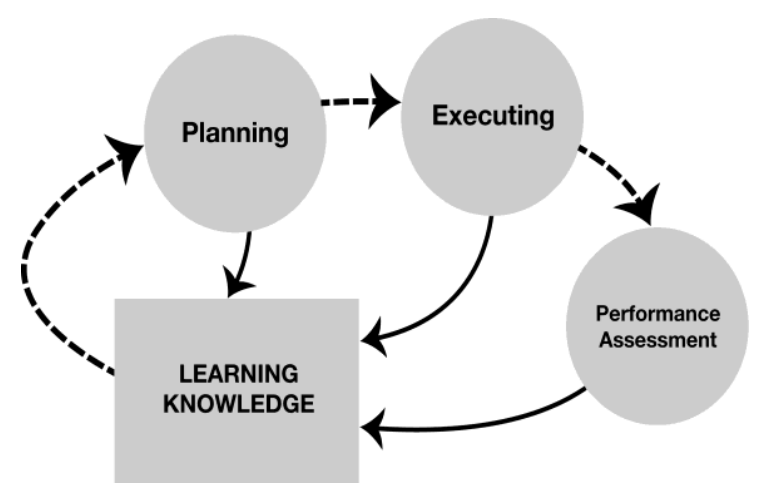

Figure 1. Learning Knowledge Feedback Loop

In December 2010, the buildingSmart alliance, a council of the National Institute of Building Sciences, (NIBS 2010)in conjunction with the BIMForum (AGC-AIA 2016)sponsored an academic workshop focused on discussing the core educational principles for technology-based collaboration in the Architecture, Engineering, Constructor, and Owner (AECO) Industry. The participants represented 21 universities and 4 countries. The papers and the panel discussions presented a state of the art view of collaboration in the AEC academy.

The keynote presentation was given by Dan Friedman, Dean of the University of Washington's College of Built Environments and president of the Association of Collegiate Schools of Architecture. His keynote called for a radical reconceptualization of AEC education. The professions must either change or perish. Change is inevitable the question is where the academy will fit in. Fragmented teaching must give way to an integrated approach. This approach must extend beyond the disciplinary skills and requires the inclusion of organizational and social sciences. It is possible to keep the disciplines core values but they must be realized in the context of collaboration.

What follows are brief reviews of the knowledge that was gained and challenges that emerged from collaborative efforts at a number of universities.

Scholars at Virginia Tech (NIBS; Pishdad et al, 2010) believe that social change defined by a 
collaborative mindset is necessary to overcome the fragmentation that exists in the industry. "Academia is in the best position to drive such transformation through re-visiting the curricula and making required adjustments." (NIBS; Pishdad et al, 2010) In order to begin this change they are in the process of developing an Integrated Real Estate Program that draws on courses from across the university. In addition, they have established the Integrated Leadership Studio (NIBS; Taiebat et al, 2010) that combines students from the AEC disciplines as well as students from sophomore through graduate studies. The upper level students lead and mentor the lower level students.

Penn State has begun two experimental courses that integrate AEC students. In order to give the programs the greatest chance of success students were required to submit their academic credentials and were interviewed as part of an application process. Despite these efforts $1 / 3$ of the teams were described as 'highly dysfunctional', and all of the teams faced challenges to collaboration. In post course analysis the instructors found a correlation between the team's collaborative abilities and the quality of the work product. Going forward it was felt that it was important to teach "...techniques which encourage successful collaboration and break down 'discipline silos' as well as the compartmentalization of the design process." (NIBS; Holland et al., 2010)

The University of Washington has developed a problem based collaborative studio that also combines ASEC students (NIBS; Dossick and Pena, 2010). In their approach much of the learning resulted from the friction that took place as the students learned to come to grips with the different disciplines. They describe the task of synthesizing the three disciplines while maintaining a real world context as 'daunting' and identified the technical issues as simple in comparison to those characterized by interdisciplinary collaboration.

The University of Oklahoma (NIBS; McCuen and Fithian, 2010) presented the results gathered over three years on an experimental intersession course that created teams of architecture and construction students. This course offering was unique in that it explicitly included exercises to socialize the students to each other's disciplines. Their experience suggests that explicit exercises in team building, while costly on the front end, pays significant dividends. In addition, it is important that the students understand these 'soft' skills as having a basis in science and there importance within their disciplines.

Kovacic (2016) describe an ongoing experiment revolving around the integration of the different building disciplines in a design course. They reported that a major enhancement to the project will be the addition of team workshops where students can learn to work together. design project focused on integration of around BIM and technology.

\section{Accreditation}

Each of the academic disciplines involved in this study is subject to accreditation by a separate organization; Accreditation Board for Engineering and Technology, Inc. (ABET) for Engineering; the National Architectural Accrediting Board (NAAB) for Architecture; and the American Council for Construction Education (ACCE) for Construction. While there is no specific owner profession, the profession of management and the main accrediting agency, the Association to Advance Collegiate Schools of Business (AACSB), is argued to be an appropriate representation for owners. Given the importance of accreditation in higher education, the standards promulgated by these bodies should have a significant impact on the philosophies, policies and procedures that define the pedagogical experience of the students.

Below are the vision or mission statements of the four accrediting agencies. Not unexpectedly their emphasis is on their distinct professions. What is noteworthy is a lack of any mention of the context in which those professions will be practiced.

- ABET will provide world leadership in assuring quality and in stimulating innovation in applied science, computing, engineering, and technology education.

- $\quad \mathrm{NAAB}$ promulgates leadership in, and the establishment of, educational quality assurance standards to enhance the value, 
relevance, and effectiveness of the architectural profession.

- ACCE is to be a leading global advocate of quality construction education programs and to promote, support, and accredit quality construction education programs.

- $\quad$ AACSB aspire(s) to be the world's leading management education authority and association.

Examination of the specific requirements for accreditation shows evidence that although the multidisciplinary context of practice is recognized; it is emphasized to varying degrees.

In the Program Outcomes for ABET EAC 'an ability to function on multidisciplinary teams' and 'an ability to communicate effectively' are two of 13 outcomes that students must attain. However, when specific programmatic requirements are examined the importance of these outcomes in comparison to technical skills is seen to decrease. In Civil Engineering programs students are required to be able to "...explain basic concepts in management, business, public policy, and leadership..." (ABET EAC 2010-2011:10, emphasis added). In Construction Engineering, an understanding of legal and professional practice issues related to the construction industry; an understanding of construction processes, communications, (ABET EAC 2010-2011:10, emphasis added). This is in contrast to mathematics, sciences, and engineering where the terms proficiency and apply knowledge that indicate functional capabilities are used. Only in Architectural Engineering is a functional level of expertise required “... an understanding of architectural design and history leading to architectural design that will permit communication, and interaction, with the other design professionals in the execution of building projects." (ABET EAC 2010-2011:7)

The NAAB defines two levels of student accomplishment (NAAB Conditions for Accreditation 2004:11) that are used to guide program development. Understanding - the assimilation and comprehension of information without necessarily being able to see its full implication, and Ability - the skill in using specific information to accomplish a task, in correctly selecting the appropriate information, and in applying it to the solution of a specific problem.

It also identifies 34 specific areas in which students must demonstrate either understanding or ability. Effective communications skills (1) are identified as a required ability, as is the ability to collaborate (7) in interdisciplinary teams. However, the collaboration is focused solely on the 'design team.' Understanding of human behavior (12) is required, but only in reference to the physical environment. Construction is referenced in terms of understanding cost control (25) and the need for understanding" ... the need for architects to provide leadership in the building design and construction process." (32) (NAAB Conditions for Accreditation 2004:11)

The ACCE requires curriculum to lead to '...a leadership role in construction ... and the application of evolving knowledge in construction and in the behavioral and quantitative sciences.' (ACCE Document 103:7) The abilities to communicate as well as understand human behavior are identified as 'essential assets'. The construction professional is identified explicitly as a manager and '.. must know how to manage the principal resources of the industry, i.e., people and money.' (Business and Management: 12) 'The Constructor must have an understanding of the contribution of the design disciplines' processes. 'The Constructor must be able to communicate with the design professionals, and should be capable of participating during the planning phase of design-build projects.' (Construction Science: 12) Curricula topics should address the constructor's role as a member of a multidisciplinary team, the assessment of project risk, and the alternate methods that can be used to structure the owner-designer-constructor team. Course work will examine the various roles and responsibilities of project participants throughout a project's life and the creative ways that project teams can be assembled. (Construction: 13)

AACSB while not speaking directly to design and construction, recognizes the importance of understanding group dynamics in Standard 9 which deals with curriculum content. The ability to work 
effectively with others in a team environment is considered a foundational skill. In addition, a basic knowledge area includes understanding group and individual behavior in organizations and society. The multidisciplinary nature of business is also emphasized in that that understanding systems and processes in organizations, including planning and design, and production/operations is also a basic knowledge area. In Standard 10 the importance of students having the opportunities to work together and learn from each other is emphasized (AACSB 2016)

The analysis above suggests that all of the disciplines acknowledge the need for multidisciplinary collaboration. However, the degree to which it is emphasized varies dramatically. In both Engineering and Architecture, the requirement is subsidiary to the achievement of design knowledge. This is in contrast to the Constructor where the development of collaborative teams is a requirement. It is also foundational to the knowledge and skill set for business.

The differences in emphasis are likely related to the licensing requirement for Architects and Engineers and must be addressed in any curriculum model. Another additional source of conflict could result from area 32 in the NAAB criteria where Architects are encouraged to take a leadership role in construction processes. Nicol and Pilling (2005) in reviewing architectural education, acknowledge that an emphasis on individual accomplishments and the studio structure is often in conflict with preparing collaborative team players.

\section{Machiavellianism}

Often described as the father of political science, Niccolo Machiavelli (1469-1527) was a fifteenth century, public bureaucrat in the Republic of Florence. In 1513, he wrote his short how-to pamphlet, The Prince, as a reflection of his years in 'public service' and as a primer for a newly designated leader of a principality. The book's short, crisp, and ruthless, but emotion-free, advice taught rulers how to acquire and keep power. Machiavelli asks the reader to consider men as they really are, as opposed to how they should be, and deal with them in a realistic manner. His "ends justify the means" theory of political science is frequently derided because of its lack of morality but is evident in practice from before Machiavelli's time to the present. Subsequently, psychologists, sociologists, and organizational behaviorists of the last forty years have taken to evaluating whether individuals employing Machiavelli's tactics and behavior are more or less successful in navigating relationships in today's world.

Seminally, Richard Christie and Florence Geis conducted an extensive review of Machiavellian practices in relation to personality in Studies in Machiavellianism (Christie 1970). In this and subsequent studies, the authors developed instruments (surveys) to measure an individual's Machiavellianism. Initially, they asked that respondents answer a statement by choosing one of three descriptors that the researchers considered least to most indicative of a Machiavellian personality. Later, they modified these instruments to present a series of statements, generally drawn from Machiavelli's The Prince, which asked respondents to answer, on a Likert Scale from "strongly disagree" to "strongly agree," their reaction to a statement drawn from Machiavelli's advice. This current instrument, the Mach IV scale, consists of a twenty statement survey.

The Machiavellianism construct is assessed using the Mach IV Scale which requires respondents to indicate their level of agreement with each of the 20 statements by using a 7-point scale that ranged from strongly disagree - neutral - strongly agree. Scores can range from 20 to 140, with higher scores indicating greater levels of Machiavellianism. A respondent who strongly disagreed with every Machiavellian view would score a 20 (Low Mach). A person who neither agreed nor disagreed with each Machiavellian view would score 80 (Med Mach). Someone who strongly agreed with every Machiavellian stance would score 140 (High Mach).

The questionnaire focuses on three themes; 1) the endorsement of manipulative tactics and deceit in interpersonal interactions; 2) cynicism about other's weakness and untrustworthiness; and 3) a disregard for conventional morality (Christie 1970) (Fehr 1992). The scale is most detailed about the respondent's views on cynicism and tactics - 
splitting 18 of its 20 questions evenly between those two categories. A person with a high score on the Mach scale - a high Mach- has confidence in his abilities to manipulate others and believes that people are easily manipulated (Athanasakopoulos 2006).

Researchers have used this instrument to attempt to tease out Machiavellian tendencies from various populations with fairly consistent results. Gabel and Topol (1991) hypothesized that "Managers who adopt manipulative behavior patterns should be more effective (run more profitable operations) than those who are not as adept in developing these behavior patterns". Their results were mixed. A significant relationship in managers' gross margin percentage, but no other statistically significant relationships were observed between Machiavellianism and job performance. Other research seems to demonstrate strong links between Machiavellianism and respondents' judgments that a particular action does not pose an ethical problem (Bass 1999, 188). Among these are: Geiss and Moon (1981); Hegarty and Sims (1978); Hunt and Chonko (1984); and Singhapakdi and Vitell (1990). The research, in general, suggests that highly Machiavellian respondents judge ambiguous actions more leniently and are more likely to form intentions to behave unethically (Bass 1999). Dahling, et al. (2009) reviewed the literature and identified a number of studies that addressed Machiavellianism and organizational criteria such as leadership, economic opportunism, defection, theft, influence tactics, job satisfaction, occupational choice and helping behaviors interpersonal tactics.

Much of the research has viewed Machiavellianism as a unitary construct. However, there is increasing evidence that it is multidimensional. Christie and Geiss (1970) implicitly acknowledged this in their recognition that there were themes in the scale. Hunter, et al. (1982) employed structural equation modeling and argued that Machiavellianism has no meaning as a unitary construct. Ahmed and Stewart (1981) identified 5 dimensions that they labeled, Machiavellian tactics, Pollyanna syndrome, Machiavellian tactics negative, Moral ideal and Machiavellian view. Corral and Calvete (2000) examined one, two, three and four factor models for Machiavellianism. Their analysis suggested a four factor model with constructs identified as; 1) Positive Interpersonal Tactics (PIT); 2) Negative Interpersonal Tactics (NIT); 3) Positive view of Human Nature (PHN); and 4) Negative view of Human Nature (NHN). These construct are theoretically consistent with earlier work where Christie (1970) had suggested the distinction between tactics (actions) and views.

\section{The Study}

Formally, this paper will examine the similarities and differences between Architectural, Engineering, Construction and Business students as it relates to their beliefs relative to behavior in an organizational setting. There are three main hypotheses that emerge from our experience and review of the literature:

- H1:(Initial Equivalence) Architectural, Engineering, Construction and Business students enter their respective professional educational paths with no differences in their attitudes as to how to behave in a group situation.

- H2:(Learning) During their education, Architectural, Engineering, Construction and Business students develop a set of attitudes relative to group behavior that is different from those that they entered with.

- H3:(Learned Differences) During their education, Architectural, Engineering, Construction and Business students develop a set of attitudes relative to group behavior that is distinct to their profession

\section{Instrumentation and Data Collection}

This study employed the Mach IV scale (Christie 1970). The scale (Table 1) was developed based on the writings of Niccolo Machiavelli and is meant to measure the political personality orientation of leaders in organizations. Political personality reflects the use of formal and informal power to control or manipulate others. The Mach IV test consists of 20 statements to which the subjects 
1) Never tell anyone the real reason you did something unless it is useful to do so.

2) The best way to handle people is to tell them what they want to hear.

3) One should take action only when sure it is morally right.

4) Most people are basically good and kind.

5) It is safest to assume that all people have a vicious streak and it will come out when they are given a chance.

6) Honesty is the best policy in all cases.

7) There is no excuse for lying to someone else.

8) Generally speaking, people won't work hard unless they're forced to do so.

9) All in all, it is better to be humble and honest than to be important and dishonest.

10) When you ask someone to do something for you, it is best to give the real reasons for wanting it rather than giving reasons which carry more weight.

11) Most people who get ahead in the world lead clean, moral lives.

12) Anyone who completely trusts anyone else is asking for trouble.

13) The biggest difference between most criminals and other people is that the criminals are stupid enough to get caught.

14) Most people are brave.

15) It is wise to flatter important people.

16) It is possible to be good in all respects.

17) P.T. Barnum was wrong when he said that there's a sucker born every minute.

18) It is hard to get ahead without cutting corners here and there.

19) People suffering from incurable diseases should have the choice of being put painlessly to death.

20) Most people forget more easily the death of their parents than the loss of their property.

Table 1: Mach IV Instrument

respond on a 7 point Likert like scale ranging from Strongly Disagree to Strongly Agree.

This study focused on students as professional cohorts. The scale was distributed to freshman and senior students in 2013, at a private college situated in the northeast United States, in each of four disciplines: Architecture, Engineering, Construction Engineering Management, and Management. The sampling results yielded eight distinct sets of responses: freshman Architecture, Engineering, Constructors and Business majors and senior Architecture, Engineering, Constructor and Business majors. Data was collected via in class completion of the survey instrument

A total of approximately 170 surveys were collected. Data was transcribed by hand from the surveys to Microsoft Excel where it was collated and categorized. Statistical analysis was conducted by importing the Excel data into STATA.

\section{Data Analysis}

The analysis was conducted in two phases. In the first phase (Pomeroy etal, (2013))
Machiavellianism was treated as a unitary construct. The differences between freshman and seniors (measured at the same time) as well as between professional cohorts were examined. Of the twelve individual cohorts, sample sizes varied from $n=13$ to $n=44$, with an average sample size of $n=24.5$. The scores are the average for each cohort and indicate that cohorts' agreement or disagreement with Machiavellian precepts. A respondent who strongly disagreed with every Machiavellian view would score a 20 (Low Mach). A person who neither agreed nor disagreed with each Machiavellian view would score 80 (Med Mach). Someone who strongly agreed with every Machiavellian stance would score 140 (High Mach). The results are presented in Table 2.

Overall, respondents scored in the Neutral/ Low Mach range with total sample mean of 71.28 for seniors and 73.07 for freshman. There was no statistically significant difference between freshman and seniors as non-differentiated cohorts. When the two groups were segmented according to discipline and year a statistically significant difference $(p<0.02)$ was observed between seniors based on discipline but not between freshman. As 


\begin{tabular}{|c|c|c|c|}
\hline & Seniors & Freshman & \\
\hline & & & \\
\hline ARCH & 68.62 & 73 & $\mathrm{~ns}$ \\
\hline CE & 65.86 & 72.04 & $\mathrm{~ns}$ \\
\hline CM & 68.54 & 75.28 & $\mathbf{0 . 0 6}$ \\
\hline BUS & 78.85 & 75.64 & $\mathrm{~ns}$ \\
\hline & $\mathbf{0 . 0 2}$ & $\mathrm{ns}$ & \\
\hline & & & \\
\hline ALL & 71.28 & 73.07 & $\mathrm{~ns}$ \\
\hline
\end{tabular}

Table 2: Overall Machiavellianism

individual cohorts the Mach index decreased from freshman to senior year for Architectural (ARCH), Engineering (CE) and Construction (CM) students. It increased for Business (BUS) students. However, the only statistically significant change (75.28 to 68.54; $p<0.06$ ) between freshman and seniors was observed between the Construction Management students.

Pairwise comparisons between the disciplines was conducted (Table 3). ANOVA with a Bonferoni adjustment (to account for the multiple comparisons) were employed to determine differences between groups. The Bonferoni adjustment is very conservative in in that errs towards minimizing Type I errors at the expense of potentially introducing Type II errors. It deflates the overall significance level $(\alpha)$ by the number of hypotheses $(m)$ tested. The result is that the

\begin{tabular}{|c|c|c|c|}
\hline \multicolumn{4}{|c|}{ Freshman } \\
\hline CM & ARCH & CM & ENG \\
\hline CE & 2.11 & \\
\hline OWN & -1.12 & -3.23 & \\
\hline \multicolumn{4}{|c|}{ Seniors } \\
\hline CM & ARCH & CM & ENG \\
\hline CE & -0.08 & \\
OWN & -2.76 & -2.68 & \\
\hline
\end{tabular}

Table 3: $\quad$ Between disciplines Machiavellianism $* p<.01$ significance level is set at $\alpha / m$. The only statistically significant difference $(p<0.03)$ was observed between Engineering and Business students. The Engineer's Mach index (65.86) was significantly lower than the Business student's index (78.85).

In terms of the hypotheses there is support for hypothesis 1 in that there is no differentiation between the freshman students. Hypothesis 2 is supported only for the construction management cohort. There is no statistically significant difference between undifferentiated seniors and freshman. Hypothesis 3 receives limited support but only in terms of the difference between business and civil engineering students.

In the second phase of the research (Puddicombe \& Patterson, 2016) Machiavellianism was treated as a multi-dimensional construct. There are a number of 'rules of thumb 'for selecting the appropriate number of dimensions. However, with a scale that has seen significant prior research, as has the MACH IV, an a priori criterion based upon theory and prior empirical research is appropriate (Cureton \& D'Agostino, 1983: Puddicombe, 2011). We therefore conducted a confirmatory factor analysis based on the work of Corral and Calvete, (2000). (The diagnostic values from different factor quantities are shown in Table 4.) They conducted a detailed examination of the structure of the Mach scale using 346 undergraduate students. They concluded that a four factor model was superior. Following their work we conducted a four factor confirmatory factor analysis with varimax rotation. As a result of that analysis items 19 and 20 were eliminated due to high uniqueness (0.94 and 0.91) respectively. Eliminating these items is also in keeping with their study in which they eliminated item 19 due to perceived changes in social mores. The results of the analysis (Table 5) closely matched their results. Using a cut-off value of $>.3$ the positive factors loaded identically. The negative factors 2 and 4 loaded as predicted except for similar loadings for variables 5,13 and 18 and item 8 loaded on Factor 2 instead of factor 4 . These results were highly consistent with their results and we therefore continued with their naming convention identifying the four factors as Factor1: 


\begin{tabular}{|ccrrr|}
\hline Factor & Eigenvalue & Difference & Proportion & Cumulative \\
Factor1 & 3.00230 & 1.41588 & 0.5416 & 0.5416 \\
Factor2 & 1.58642 & 0.65752 & 0.2862 & 0.8278 \\
Factor3 & 0.92890 & 0.39930 & 0.1676 & 0.9954 \\
Factor4 & 0.52960 & 0.10536 & 0.0955 & 1.0909 \\
Factor5 & 0.42425 & 0.21483 & 0.0765 & 1.1675 \\
Factor6 & 0.20942 & 0.04565 & 0.0378 & 1.2052 \\
Factor7 & 0.16377 & 0.02723 & 0.0295 & 1.2348 \\
Factor8 & 0.13654 & 0.09434 & 0.0246 & 1.2594 \\
Factor9 & 0.04220 & 0.01461 & 0.0076 & 1.2670 \\
Factor10 & 0.02759 & 0.06057 & 0.0050 & 1.2720 \\
Factor11 & -0.03298 & 0.06951 & -0.0060 & 1.2661 \\
Factor12 & -0.10249 & 0.01477 & -0.0185 & 1.2476 \\
Factor13 & -0.11726 & 0.05489 & -0.0212 & 1.2264 \\
Factor14 & -0.17215 & 0.03586 & -0.0311 & 1.1954 \\
Factor15 & -0.20801 & 0.05470 & -0.0375 & 1.1578 \\
Factor16 & -0.26271 & 0.02343 & -0.0474 & 1.1104 \\
Factor17 & -0.28614 & 0.03992 & -0.0516 & 1.0588 \\
Factor18 & -0.32606 &. & -0.0588 & 1.0000 \\
\hline
\end{tabular}

Table 4: Factor Diagnostics

\begin{tabular}{|l|rrrr|r|}
\hline Variable & Factor1 & \multicolumn{1}{|c|}{ Factor2 } & \multicolumn{1}{c|}{ Factor3 } & Factor4 & Uniquenes \\
\hline Q1 & -0.2251 & $\mathbf{0 . 5 4 0 1}$ & 0.0223 & 0.0805 & 0.6507 \\
Q2 & -0.0898 & $\mathbf{0 . 7 0 4 4}$ & 0.0412 & -0.0234 & 0.4935 \\
Q3 & $\mathbf{0 . 3 5 4 5}$ & 0.2205 & 0.0437 & -0.2109 & 0.7793 \\
Q4 & 0.1349 & -0.0200 & $\mathbf{0 . 5 5 3 6}$ & -0.1849 & 0.6408 \\
Q5 & 0.0271 & $\mathbf{0 . 3 8 0 9}$ & -0.1162 & $\mathbf{0 . 3 7 5 0}$ & 0.7000 \\
Q6 & $\mathbf{0 . 6 7 4 5}$ & -0.1062 & 0.2781 & 0.0116 & 0.4563 \\
Q7 & $\mathbf{0 . 6 8 5 8}$ & -0.0488 & -0.0619 & -0.0706 & 0.5184 \\
Q8 & 0.0242 & $\mathbf{0 . 4 7 5 9}$ & -0.1530 & 0.1815 & 0.7166 \\
Q9 & $\mathbf{0 . 5 2 6 1}$ & -0.1999 & 0.1179 & -0.0763 & 0.6636 \\
Q10 & $\mathbf{0 . 3 9 3 6}$ & -0.0301 & 0.2160 & 0.0128 & 0.7974 \\
Q11 & 0.1665 & 0.0742 & $\mathbf{0 . 4 1 9 9}$ & 0.1416 & 0.7704 \\
Q12 & -0.1894 & 0.1373 & -0.2391 & $\mathbf{0 . 3 9 3 5}$ & 0.7332 \\
Q13 & 0.0135 & $\mathbf{0 . 4 3 9 3}$ & -0.0629 & $\mathbf{0 . 4 8 6 9}$ & 0.5658 \\
Q14 & 0.1452 & -0.0119 & $\mathbf{0 . 5 5 7 0}$ & -0.1552 & 0.6444 \\
Q15 & -0.1236 & $\mathbf{0 . 3 4 9 2}$ & 0.1933 & 0.1933 & 0.7880 \\
Q16 & $\mathbf{0 . 4 7 7 2}$ & 0.0057 & 0.0786 & -0.1842 & 0.7322 \\
Q17 & 0.1551 & 0.1699 & 0.2726 & -0.4637 & 0.6578 \\
Q18 & -0.3080 & $\mathbf{0 . 3 3 7 6}$ & -0.0342 & $\mathbf{0 . 3 8 1 7}$ & 0.6443 \\
\hline
\end{tabular}

Table 5: Four Factor Loadings

Positive Interpersonal Tactics (PIT); Factor2: Negative Interpersonal Tactics (NIT), Factor3: Positive view of Human Nature (PHN), and Factor4: Cynical view of Human Nature (CHN).

The factors measure Machiavellian action (tactics) and Machiavellian beliefs (views). They also recognize the potential for a social desirability bias in that respondents may react more negatively to what they perceive as inappropriate beliefs and actions as compared to their positive reaction to what they perceive as appropriate beliefs and actions. A positive score for factors 1 and 3 would be consistent with negative scores for factors 2 and 4 . However the intensity of the score may vary.

Factor scores, which are linear composites for each factor for each respondent, were then computed following a 'refined regression' approach (DiStefano, Zhu \& Mindrila, 2009). In developing these scores the factor analysis was employed to compute a regression scoring coefficients for each factor (Table 6). Each student's response was standardized to a variable with zero mean and unit variance. Each variable was then weighted by its scoring coefficient and the results were summed for each factor for each respondent. The summary results from this process are seen in Tables 7 and 8.

These scores were then employed to conduct the cohort analyses in the same manner as had previously been conducted with the MACH index. Tables 9 and 10 consolidate the results of the analysis. These results show a much more nuanced set of relationships. In terms of the overall cohort: Freshmen differ on CHN while seniors differ on PIT, PHN and CHN. When the disciplinary cohorts are examined each discipline varies on a 


\begin{tabular}{|c|c|c|c|c|}
\hline Variable & Factor1 & Factor2 & Factor3 & Factor4 \\
\hline Q1 & -0.06044 & 0.21345 & 0.02723 & -0.03746 \\
\hline Q2 & -0.00640 & 0.37604 & 0.01568 & -0.14358 \\
\hline Q3 & 0.11068 & 0.12343 & -0.04316 & -0.12142 \\
\hline Q4 & -0.01336 & 0.00699 & 0.29453 & -0.03907 \\
\hline Q5 & 0.10114 & 0.12152 & -0.05082 & 0.17858 \\
\hline Q6 & 0.29233 & -0.02912 & 0.14861 & 0.14065 \\
\hline Q7 & 0.35180 & 0.03721 & -0.17995 & -0.00013 \\
\hline Q8 & 0.05212 & 0.18094 & -0.08884 & 0.02407 \\
\hline Q9 & 0.17291 & -0.05484 & 0.00388 & 0.02982 \\
\hline Q10 & 0.10213 & -0.00295 & 0.07960 & 0.05589 \\
\hline Q11 & 0.00835 & 0.00524 & 0.22243 & 0.12175 \\
\hline Q12 & -0.01193 & -0.00452 & -0.06319 & 0.18098 \\
\hline Q13 & 0.07816 & 0.14735 & 0.01075 & 0.27636 \\
\hline Q14 & -0.01401 & 0.00687 & 0.30093 & -0.00775 \\
\hline Q15 & -0.03286 & 0.09079 & 0.12301 & 0.07366 \\
\hline Q16 & 0.15555 & 0.04988 & -0.03331 & -0.07908 \\
\hline Q17 & 0.00879 & 0.13661 & 0.09173 & -0.27487 \\
\hline Q18 & -0.07910 & 0.07213 & 0.05466 & 0.17564 \\
\hline
\end{tabular}

Table 6: Scoring Coefficients specific dimension. Business varies on PIT, Construction Managers vary on NIT, Civil Engineers vary on PHN and Architects vary on CHN. In all cases, except business, the trend from freshman to senior is towards a less Machiavellian perspective.

In Table 9 we see support for Hypothesis 1 in that there is no statistically significant difference in the freshman cohorts with the exception of CHN. In Table 10 that difference $(p<.06)$ is seen to be between Civil freshman ($.23)$ and Business freshman (.25). Hypothesis 2 is supported only for specific cohorts and specific constructs.

- The business students moved from a neutral position $(0)$ on positive tactics to a negative view (-.4).

- The Construction Management students moved from a positive position (.19) on negative tactics to a negative view (-.43).

- The Civil Engineering students moved from a negative position (-.07) on positive human nature to a positive view (.39).

- The Architecture moved from a negative position (.19) on cynical human nature to a more negative view (-.47).

\begin{tabular}{|c|rrrrr|}
\hline Variable & Obs & Mean & Std. Dev. & \multicolumn{1}{l}{ Min } & \multicolumn{1}{l|}{ Max } \\
\multicolumn{1}{|c}{} & & & & & \\
\hline PIT & $\mathbf{1 6 3}$ & $\mathbf{1 . 9 1 E - 0 9}$ & $\mathbf{0 . 8 5 5 5 3 0 5}$ & $\mathbf{- 2 . 9 0 0 5 8 3}$ & $\mathbf{1 . 5 5 6 7 3 2}$ \\
NIT & $\mathbf{1 6 3}$ & $-\mathbf{1 . 4 9 E}-09$ & $\mathbf{0 . 8 3 4 2 1 5 1}$ & $\mathbf{- 2 . 0 0 6 4 3 5}$ & $\mathbf{2 . 5 3 2 9 1 1}$ \\
PHN & 163 & $\mathbf{1 . 3 0 E - 0 9}$ & $\mathbf{0 . 7 5 6 1 5 9 3}$ & $\mathbf{- 1 . 9 7 5 0 9 5}$ & $\mathbf{2 . 1 4 0 6}$ \\
CHN & $\mathbf{1 6 3}$ & $-\mathbf{- 7 . 8 6 E - 1 0}$ & $\mathbf{0 . 7 4 3 0 3 1 6}$ & $\mathbf{- 1 . 8 3 0 2 1 4}$ & $\mathbf{2 . 8 5 2 4 8 1}$ \\
\hline
\end{tabular}

Table 7: Summary Data

\begin{tabular}{|l|rlcr|}
\hline & \multicolumn{1}{|l}{ PIT } & NIT & PHN & NHN \\
& & & & \\
\hline PIT & $\mathbf{1 . 0 0 0 0}$ & & & \\
NIT & $\mathbf{- 0 . 0 5 2 3}$ & $\mathbf{1 . 0 0 0 0}$ & & \\
PHN & $\mathbf{0 . 1 2 7 8}$ & $\mathbf{0 . 0 3 8 5}$ & $\mathbf{1 . 0 0 0 0}$ & \\
CHN & $\mathbf{- 0 . 0 6 9 3}$ & $\mathbf{0 . 1 6 5 9}$ & $\mathbf{- 0 . 1 6 0 5}$ & $\mathbf{1 . 0 0 0 0}$ \\
\hline
\end{tabular}

Table 8: Correlation Matrix
There is no statistically significant difference between undifferentiated seniors and freshman. Table 11 consolidates these results.

Hypothesis 3 is also narrowly supported. As can be seen in Table 10 (at the senior level) each discipline differs from another, not overall, but on a specific factor.

There is a significant difference on positive tactics between the Construction Management students (.41) and the Business students (-.4).

There are no differences on negative tactics.

There is a significant difference on positive human nature between the Civil Engineering students (.39) and the Business students (-.16). 


\begin{tabular}{|c|c|c|c|c|c|c|c|c|c|c|c|c|}
\hline & & PIT & & & NIT & & & PHN & & & $\mathrm{CHN}$ & \\
\hline & Seniors & Freshmar & & Seniors & Freshma & & Seniors & Freshmar & & Seniors & Freshma & \\
\hline $\mathrm{ARCH}$ & 0.01 & -0.17 & $\mathrm{~ns}$ & -0.03 & -0.22 & ns & 0.02 & -0.02 & ns & -0.47 & -0.13 & 0.07 \\
\hline $\mathrm{CE}$ & 0.25 & -0.04 & ns & -0.22 & 0.03 & ns & 0.39 & -0.07 & 0.1 & -0.17 & -0.23 & $\mathrm{~ns}$ \\
\hline $\mathrm{CM}$ & 0.41 & 0.18 & $\mathrm{~ns}$ & -0.43 & 0.19 & 0.03 & 0.02 & -0.29 & $\mathrm{~ns}$ & 0.18 & 0.16 & $\mathrm{~ns}$ \\
\hline BUS & -0.4 & 0 & 0.09 & 0.09 & 0.18 & ns & -0.16 & 0.11 & ns & 0.15 & 0.25 & ns \\
\hline & 0.02 & ns & & ns & ns & & 0.08 & $\mathrm{~ns}$ & & 0.02 & 0.04 & \\
\hline ALL & 0.01 & 0 & ns & -0.12 & 0.07 & ns & 0.04 & -0.02 & ns & -0.07 & 0.04 & ns \\
\hline
\end{tabular}

Table 9: Initial Equivalence and Learning

\begin{tabular}{|c|c|c|c|c|c|c|c|c|c|c|c|c|c|c|c|}
\hline \multicolumn{4}{|c|}{ PIT } & \multicolumn{4}{|c|}{ NIT } & \multicolumn{4}{|c|}{ PHN } & \multicolumn{4}{|c|}{$\mathrm{CHN}$} \\
\hline \multicolumn{16}{|c|}{ Freshman } \\
\hline & ARCH & $\mathrm{CM}$ & ENG & & $\mathrm{ARCH}$ & $\mathrm{CM}$ & ENG & & ARCH & $\mathrm{CM}$ & ENG & & $\mathrm{ARCH}$ & $\mathrm{CM}$ & ENG \\
\hline $\mathrm{CM}$ & 0.35 & & & $\mathrm{CM}$ & 0.41 & & & $\mathrm{CM}$ & -0.26 & & & $\mathrm{CM}$ & 0.29 & & \\
\hline $\mathrm{CE}$ & 0.13 & -0.22 & & $\mathrm{CE}$ & 0.25 & 0.16 & & $\mathrm{CE}$ & -0.04 & 0.21 & & $\mathrm{CE}$ & -0.1 & -0.39 & \\
\hline OWN & 0.17 & -0.18 & 0.03 & OWN & 0.41 & 0.00 & 0.15 & OWN & 0.14 & 0.41 & 0.19 & OWN & 0.38 & -0.09 & 0.49 \\
\hline \multicolumn{16}{|c|}{ Seniors } \\
\hline & $\mathrm{ARCH}$ & $\mathrm{CM}$ & ENG & & $\mathrm{ARCH}$ & $\mathrm{CM}$ & ENG & & $\mathrm{ARCH}$ & $\mathrm{CM}$ & ENG & & $\mathrm{ARCH}$ & $\mathrm{CM}$ & ENG \\
\hline $\mathrm{CM}$ & 0.40 & & & $\mathrm{CM}$ & -0.40 & & & $\mathrm{CM}$ & 0.00 & & & $\mathrm{CM}$ & ${ }^{*} 0.65$ & & \\
\hline $\mathrm{CE}$ & 0.24 & -0.16 & & $\mathrm{CE}$ & -0.19 & 0.21 & & CE & 0.37 & 0.37 & & CE & 0.3 & -0.35 & \\
\hline OWN & -0.41 & $*-0.82$ & -0.65 & OWN & 0.13 & 0.53 & 0.32 & OWN & 0.18 & -0.19 & ${ }^{*}-0.56$ & OWN & $* 0.63$ & -0.02 & 0.32 \\
\hline
\end{tabular}

Table 10: Pairwise Comparisons $* p<.1$

\begin{tabular}{|c|c|c|c|}
\hline & Seniors & Freshman & \\
\hline CM & 68.54 & 75.28 & Mach \\
\hline ARCH & -0.47 & -0.13 & CHN \\
\hline CE & 0.39 & -0.07 & PHN \\
\hline CM & -0.43 & 0.19 & NIT \\
\hline BUS & -0.4 & 0 & PIT \\
\hline
\end{tabular}

Table 11: Hypothesis 2 Consolidated Results

\begin{tabular}{|c|c|c|c|}
\hline \multicolumn{4}{|c|}{ SENIORS } \\
\hline & CE & CM & BUS \\
\hline ARCH & na & CHN & CHN \\
\hline CE & & Na & Mach/PHN \\
\hline CM & & & PIT \\
\hline
\end{tabular}

Table 12: Hypothesis 3 Consolidated Results

There is a significant difference on cynical human nature between the Architecture (-.47) and the Business students (.15) and Construction Management students (.18)

\section{Discussion:}

The results suggest that students do change from their freshman to senior years in terms of their perceptions as to what is appropriate inter-personal behavior. However, the change is more nuisance than hypothesized. While all the disciplines exhibited a neutral to slightly low overall Mach tendency during the freshman year only the Construction students exhibited a significant change. While they were not significantly different from the overall senior cohort they decreased their Mach score from freshman to senior year.

Understanding the pattern of change in the four factors requires an examination of the theoretical underpinnings of the factors. In the original work on Machiavellianism (Christie and Geis, 1970) it was suggested that there was a difference in how individuals would respond when the metrics referred to actions as opposed to beliefs. An agreement with a high Mach perspective on human nature did not necessarily translate into agreement with Machiavellian actions.

Table 12 consolidates these results. 
As discussed above Architectural students had a significant increase in their rejection of a cynical view of human nature, and it is significantly different from the slightly positive response from the Construction and the Business cohorts. However, there was no such change in the other three factors and their scores were statistically no different than those of the other cohorts. Interestingly we can see that as seniors they held a basically neutral view on the other 3 factors $(.01$, $.03, .02)$. Architecture seniors occupied the middle ground in their perspective on both positive and negative actions as well as their perspective on positive perspectives on human nature. However, they strongly rejected a negative view.

As discussed above the Engineering students had a significant increase in their support for a positive view of human nature and it was significantly different from the Business cohort's rejection of this view. However, there was no such change in the other three factors and their scores were statistically no different than those of the other cohorts. In total the engineers supported a positive and rejected a negative perspective of both actions and human nature $(.25,-.22, .39,-.17)$.

As discussed above the Construction students had a significant increase in their rejection of Machiavellian tactics but it was not significantly different from the other cohorts. However, there was no such change in the other three factors and their scores were no different than those of the other cohorts. They exhibit the strongest acceptance (.41) and the strongest rejection (.43) of positive and negative actions. In terms of their views of human nature they were neutral (.02) in relationship to a positive and supported (.18) a cynical view.

As discussed above the Business students had a significant increase in their rejection of positive tactics and it was significantly different from the Construction cohort. However, there was no such change in the other three factors and their scores were no different than those of the other cohorts. The business students had the most Machiavellian perspective. They rejected a positive and supported a negative perspective of both actions and human nature $(.-.4, .09,-.016, .15)$.
Considering a positive PIT and a negative NIT and a positive PHN and a negative NHN conceptually equivalent we see some interesting outcomes. Architectural and Engineering students changed relative to beliefs, both exhibiting lower Mach tendencies. The Architects were lower than both the Construction and Business cohorts and the Engineers were lower than the Business cohort. There was no difference between the Architects and Engineers. Construction and Business students changed relative to actions. Construction students exhibited lower Mach tendencies relative to action while Business students exhibited higher Mach tendencies. The Construction cohort was lower than the Business cohort and there was no difference between Architects and Engineers.

If we were to generalize on the results: Students enter the academy without cohort specific differences as to their views of appropriate interpersonal behavior. As they progress through their education Architects and Engineers develop a more positive perspective on human nature than they began with. Constructors develop a stronger set of beliefs in relationship to interpersonal tactics. The business cohort exhibits the opposite tendency and is more supportive of Machiavellian tactics.

These changes are evidenced in the differences exhibited in their senior year. Architects and Engineers place a greater emphasis on beliefs than on actions. The Construction cohort is focused on tactics and consistently supports positive and rejects negative tactics. The Business cohort also focuses on tactics but takes a more Machiavellian view by disagreeing with positive tactics.

While the focus of the research has been change during the educational process, the questions were driven by a desire to understand the often contentious relationships that exist between the actors as they interact in realizing the built environment. With the caveat that an actor's behavior is driven by a host of factors including their experiences in industry as well as the tacit knowledge they acquire while in school some provocative generalizations can be made from the results. Table 13 graphically and numerically presents the consolidated senior results which drives these statements. 


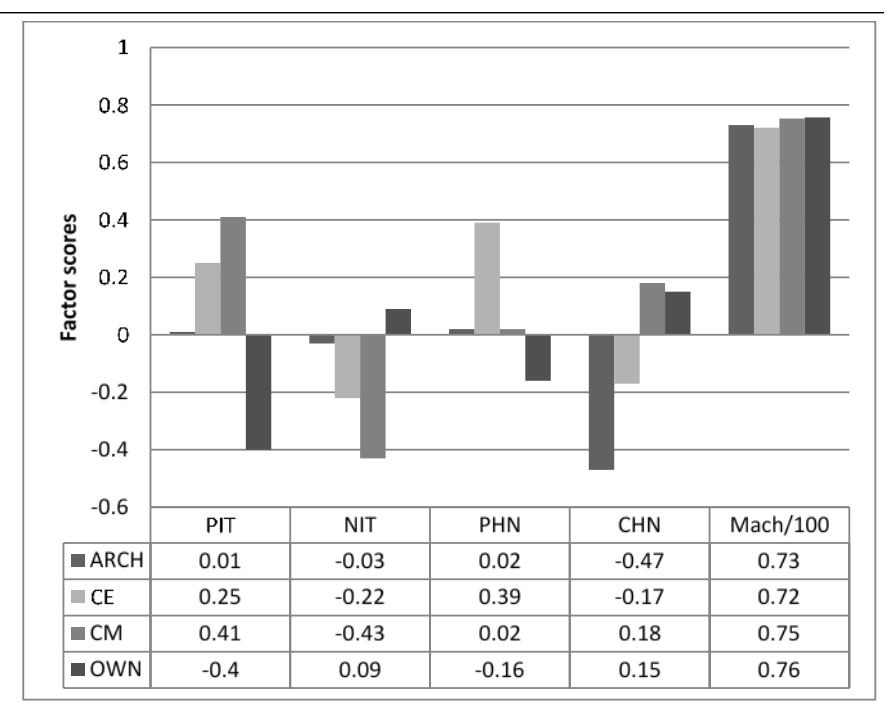

Table 13: Consolidated Sector Results

- Architects as opposed to being altruistic appear to maintain a middle ground in their perspective. The only place that they take a stand is in rejecting a cynical perspective of human nature, but they do this without supporting a positive view. Architects are neutral on human nature and actions.

- Engineers as opposed to being pragmatic take an altruistic perspective. They support positive actions and beliefs as well as rejecting negative actions and beliefs. Engineers are positive on human nature and support positive actions.

- Constructors stereotypically might be expected to behave in a Machiavellian manner, however this is not the case. While they weakly support a negative view of human nature they also strongly support positive actions. In fact, their perspective on actions is the greatest on both their support for positive and their rejection of negative actions. While Constructors might have a slightly cynical view of human nature they support positive actions.

- Business stereotypically would be considered to have a tendency towards
Machiavellianism and the results support this perspective. They support negative actions and beliefs as well as rejecting positive actions and beliefs. Business is negative on human nature and support negative actions.

\section{Conclusion}

The results of this analysis while mixed in their support of the specific hypothesis give credence to the need for a more active consideration of the interpersonal skills that students develop. Taking a slightly biased perspective we would hope that our students develop a set of beliefs about behavior (NIT and PIT) that supported collaboration. Likewise, given that our belief systems will impact how we perceive the behavior of others, we would hope that our students exhibited a positive set of beliefs about human nature (PHN and CHN). Future research should examine the factors in the educational process that produce the outcomes seen in this study.

The results also suggest that viewing Machiavellianism as a multi-dimensional construct that focuses on actions and beliefs is appropriate. The differences that were observed on these constructs indicate that further research in this direction could yield a greater understanding of the dynamics that occur in AECO organizations. It is suggested that future research build on and test this model.

Lastly in the discussion session the results were expanded to characterize the different disciplines. While it is acknowledged that these characterizations are suspect they provide a stepping off point for future research.

There are 2 major caveats to this research. One is that it reports on a single university. This makes generalizability difficult. Research that spans more institutions is necessary and we are currently in the process of gathering information from other schools. Additionally, the current research was conducted at a single period in time. Recognizing this we have recently collected data on the senior 
cohort that was the freshman cohort in this study and we are currently conducting a longitudinal analysis.

Collaboration does not just happen. Interdisciplinary skills do not just appear. Both have to be planned and learned. The members of the academy have a significant responsibility for preparing students who have both the hard and the soft skills required to be successful in creating the built environment.

\section{References}

AACSB. Association to Advance Collegiate Schools of Business. 2016. http://www.aacsb.edu/ (accessed March 31, 2016).

AGC-AIA. BIMForum. 2016. http://bimforum.org/ (accessed March 31, 2016).

Ahmed, S. and Stewart, R. (1981) "Factor Analysis of the Machiavellian Scale." Social Behavior and Personality, vol. 9, no. 113-115.

Arnold, H. J., \& Feldman, D. C. (1981) "Social desirability response bias in self-report choice situations." Academy of Management Journal, 377385.

Athanasakopoulos, G. and Letzler, R. (2006) "Linking High Machiavellians and Free Riding Types in Public Goods Experiments." berkley.edu. http://www.ocf.berkeley.edu/ rj1/Athanasakopoulos _Letzler_mach_and_free_riding.pdf (accessed Mar 15, 2013).

Bass, K., Barnett, T. and Brown, G. (1999)"Individual Difference Variables, Ethical Judgments, and Ethical Behavioral Intentions." Business Ethics Quarterly, Vol. 9, No. 2, 183-205.

Chinowsky, P and Brown, H (2004) The development of successful intelligence in construction education. In: Khosrowshahi, F (Ed.), 20th Annual ARCOM Conference, 1-3 September 2004, Heriot Watt University. Association of Researchers in Construction Management, Vol. 1, 525-32.

Christie, R. and Geis, F. (1970) Studies in Machiavellianism. New Yor: Academic Press.

ConsensusDocs. 2016. https://www.consensusdocs.org/ (accessed March 31, 2016).

Corral, S, and E Calvete. (200) "Machiavellianism: Dimensionality of the Mach IV and its relation to self-monitoring in a Spanish sample." The Spanish journal of psychology, 3-13.

Crowne, D. P., \& Marlowe, D. (1964) The approval motive: Studies in evaluative dependence. New York: Wiley.
Cureton, E. and D'Agostino, R., (1983) Factor Analysis: an Applied Approach, Hillsdale, NJ: Lawrence Erlbaum Associates.

Dahling, JJ, BG Whitaker, and PE Levy. (2009) "The development and validation of a new Machiavellianism scale." Journal of Management, 219-257.

DiStefano, C., Zhu, M. and Mindrila, D., (2009) 'Understanding and Using Factor Scores: Consideration for the Applied Researcher', Practical Assessment, Research and Evaluation, 14:20, 1-11

Dougherty, D. (1992) "Interpretive barriers to successful product innovations in large firms." Organizational Science, Vol 3(2), 179-202.

Egan, J. (1998) "Rethinking Construction" Construction Task Force to the Deputy Prime Minister, John Prescott

Emmit, S and Goarse, C. (2007) 'Communication in Construction Teams', London: Taylor and Francis, 2007.

Fehr, B., Sampson, D., and Paulhus, D. (1992) "The construct of Machiavellianism:Twenty years later"." In Advances in personality assessment, Vol 9., by C., and J. Butcher, J. (Eds.) Spielberger, 77-116. Hillsdale, NJ: Lawrence Erlbaum.

Fernandez-Solis, J. (2009) "How the Construction Industry does Differ from Manufacturing?" Associated Schools of Construction International Proceedings of the 45th Annual Conference. Gainesville, FL.

Gabel, M. and Topol, M. (1991) "Machiavellian Managers: Do They Perform Better?"." Journal of Business and Psychology, Vol. 5, No. 3, 355-365.

Gameson, R.N. (1992) 'An investigation into the interaction between potential building clients and construction professionals, http://ethos.bl.uk/OrderDetails.do?uin=uk.bl.ethos.3 32820 (accessed 2015).

Geis, F. L., and Moon, T. H. (1981) "Machiavellianism and deception." Journal of Personality and Social Psychology Vol. 41, 1981: 766-775.

Hegarty, W. H., and Sims, H. R, Jr. (1978) "Some determinants of unethical decision behavior: An experiment."." Journal of Applied Psychology No. 63 , 451-457.

Hunt, S., and Chonko, L. (1984) "Marketing and Machiavellianism."Journal of Marketing, Vol. 48, 30-42.

Kreis, Steven. (2007) "Niccolo Machiavelli, 14691527." The History Guide. Mar 11, 2007. http://www.historyguide.org/intellect/machiavelli.ht ml (accessed Mar 11, 2013).

Lavikka, R., Lehtinen, T., Hall, D. (2016). "Co-Creation of Digital Services with and for Facilities Management in Construction Projects", Working 
Paper Series, Proceedings of the Engineering Project Organization Conference, Cle Elum, WA, June 28-30, 2016.

Latham, M. (1994) "Constructing the Team" HMSO

Lindebaum, D., Cassell, C., (2012) "A Contradiction in Terms? Making Sense of Emotional Intelligence in a Construction Management Environment" British Journal of Management, Vol. 23, 65-79.

Lindebaum, D., Jordan, P. (2012) "Relevant but exaggerated: the effects of emotional intelligence on project manager performance in construction" Construction Management and Economics 30:7

Liu, A. (2006)"Work Empowerment as an Antecedent to Organizational commitment in the Hong Kong Quality Surveying Profession." Surveying and Built Environment Vol 17(2), 63-72.

Loosemore, M. (1994) "Problem Behaviour." Construction Management and Economics. Vol 12, 511-520.

Love, P., Irani, Z., \& Edwards, D. (2004) "A Seamless Supply Chain Management Model for Construction." Supply Chain Management: An International Journal. 9:1 43-56.

Mo, Y, Dainty, A and Price, A (2007) An assessment of the emotional intelligence of construction students: an empirical investigation. In: Boyd, D (Ed) Procs 23rd Annual ARCOM Conference, 3-5 September 2007, Belfast, UK, Association of Researchers in Construction Management, 325-334.

Murray, M. \& Langford, D. (2009) "Collegiality in the Scottish Construction Industry: Are Jock Tamson's Bairs Held Together by Surface Tension?" Danity, A (ed.) Proceedings, 25th Annual ARCOM Conference, 7-9 September 2009. Nottingham, UK : Association of Resarchers in Construction Management, 2009. NIBS. 2010. https://www.nibs.org/?page=bsa_proceedings (accessed 2011).

Patterson, J., Morton, D., \& Griffin, K. (2008) Quality and Construction - How to Develop a Quality
Management System for Your Construction Firm. Vista, CA: : BNi, Publications, Inc., 2008.

Pomeroy, S, J Patterson, M Puddicombe, A Temkin, and E Schmecpeper. (2013) "The foundations of Multidisciplinary Behavior." Working Paper Series, Proceedings of the Engineering Project Organization Conference. Winter Park: EPOC, 2013.

Puddicombe, M. (1997) "Designers and Contractors: Impediment to Integration. ." Journal of Construction Engineering and Management, 245252.

Puddicombe, M. (2009) "Why Contracts: Evidence." Journal of Construction Engineering and Management, 675-682.

Puddicombe, M. (2011) "The Contingencies of Project Management: A Factor Analytic Approach to Complexity and Novelty", International Journal of Construction Education and Research, 7:4, 259-275

Singhapakdi, A., and Vitell, S. J. (1990)"Marketing ethics: Factors influencing perceptions of ethical problems and alternatives."." Journal of Macromarketing, Vol. 10, No. 1, 4-18.

Songer, A D and Walker, B (2004) General contractor emotional intelligence in the construction industry. In: Khosrowshahi, F (Ed.), 20th Annual ARCOM Conference, 1-3 September 2004, Heriot Watt University. Association of Researchers in Construction Management, Vol. 1, 487-93.

Songer, A., Chinowsky, P., Butler, C., (2006) 'Emotional Intelligence and Leadership Behavior in Construction Executives', 2ND Specialty Conference on Leadership and management in Construction

Sonnenwald, Diane H., and Pierce, Linda G. (2000) "Information behavior in dynamic group work contexts: interwoven situational awareness, dense social networks and contested collaboration in command and control." Information Processing and Management: an International Journal, 36:3, 461479. 